\title{
Emotional predictors of bowel screening: the avoidance-promoting role of fear, embarrassment, and disgust
}

\author{
Lisa M. Reynolds ${ }^{1^{*}} \mathbb{D}$, lan P. Bissett ${ }^{2}$ and Nathan S. Consedine ${ }^{1}$
}

\begin{abstract}
Background: Despite considerable efforts to address practical barriers, colorectal cancer screening numbers are often low. People do not always act rationally, and investigating emotions may offer insight into the avoidance of screening. The current work assessed whether fear, embarrassment, and disgust predicted colorectal cancer screening avoidance.
\end{abstract}

Methods: A community sample $(N=306)$ aged $45+$ completed a questionnaire assessing colorectal cancer screening history and the extent that perceptions of cancer risk, colorectal cancer knowledge, doctor discussions, and a specifically developed scale, the Emotional Barriers to Bowel Screening (EBBS), were associated with previous screening behaviours and anticipated bowel health decision-making.

Results: Step-wise logistic regression models revealed that a decision to delay seeking healthcare in the hypothetical presence of bowel symptoms was less likely in people who had discussed risk with their doctor, whereas greater colorectal cancer knowledge and greater fear of a negative outcome predicted greater likelihood of delay. Having previously provided a faecal sample was predicted by discussions about risk with a doctor, older age, and greater embarrassment, whereas perceptions of lower risk predicted a lower likelihood. Likewise, greater insertion disgust predicted a lower likelihood of having had an invasive bowel screening test in the previous 5 years.

Conclusions: Alongside medical and demographic factors, fear, embarrassment and disgust are worthy of consideration in colorectal cancer screening. Understanding how specific emotions impact screening decisions and behaviour is an important direction for future work and has potential to inform screening development and communications in bowel health.

Keywords: Screening, Colorectal cancer, Emotion, Disgust, Fear, Embarrassment, Avoidance

\section{Background}

Colorectal cancer (CRC) is the third most common cancer worldwide and the fourth leading cause of cancer-related deaths [1]. CRC screening has been shown to reduce incidence and mortality through the early identification of cancer and high risk polyps [2]. In recent years, many organised population-based screening programmes have been implemented or are being progressively rolled out across regions [3]. Screening

\footnotetext{
* Correspondence: I.reynolds@auckland.ac.nz

'Department of Psychological Medicine, The University of Auckland, Private

bag 92019, Victoria Street West, Auckland 1142, New Zealand

Full list of author information is available at the end of the article
}

guidelines vary but generally concur insofar as they suggest that organised programmes should utilise a combination of annual/bi-annual testing for blood in the stool (e.g., FOBT) and less frequent bowel scope screening (e. g., colonoscopy) from the age of approximately 50 in average risk persons $[4,5]$. Considerable efforts have been directed towards facilitating uptake of such screening. A systematic review of interventions aimed at increasing access to screening suggest a global focus on reducing structural barriers to screening tests including driving mobile units to worksites and communities, reducing administrative demands, and offering screenings at subsidised rates or for no charge [6]. However, despite

(c) The Author(s). 2018 Open Access This article is distributed under the terms of the Creative Commons Attribution 4.0 International License (http://creativecommons.org/licenses/by/4.0/), which permits unrestricted use, distribution, and reproduction in any medium, provided you give appropriate credit to the original author(s) and the source, provide a link to the Creative Commons license, and indicate if changes were made. The Creative Commons Public Domain Dedication waiver (http://creativecommons.org/publicdomain/zero/1.0/) applies to the data made available in this article, unless otherwise stated. 
established benefits, even when screenings are free and accessible, many people continue to avoid them [7]. Participation in CRC screening programmes varies widely and a recent review of international uptake for organised screening programmes reported that participation ranged from 7 to $68 \%$ [8]. A parallel line of study has evaluated how emotions-based research may increase understanding of why people reject medical investigations they ought to attend [9]. Below, we continue in this endeavour, presenting a report investigating possible emotional (fear, embarrassment, and disgust) barriers to colorectal cancer (CRC) screening where, despite the benefits of early detection [10], screening rates are low.

There are strong reasons to suspect that the avoidancepromoting emotions of fear, embarrassment, and the lessstudied disgust may act as barriers to CRC screening. In the evolutionary view, fear, embarrassment, and disgust are all emotions that specifically evolved to promote avoidance. Functionally, fear reduces danger by urging us to flee [9], embarrassment reduces the threat of exclusion by forestalling social norm violation [11], and disgust promotes health by motivating the avoidance of potential contaminants [12]. Prima facie, most CRC screenings and medical investigations involve exposure to the elicitors of all three of these feelings. Colonoscopies, for example, involve inserting apparatus into the anus and may involve pain and the threat of a cancer diagnosis (fear), the display of private body parts (embarrassment), and exposure to potential contaminants like faeces (disgust).

Fear and embarrassment have received some empirical attention in prior CRC work; fear of a cancer diagnosis $[13,14]$ and embarrassment from intimacy [15], especially where the physician is of a different gender [15], predict lower CRC screening. While disgust has been mostly overlooked, there are a few recent studies implying disgust-generated avoidance in CRC screening [12, 16, 17]. However, while studies of fear, embarrassment and disgust are developing, individual studies have typically focussed on single avoidance-promoting emotions in isolation without considering multiple emotions concurrently. This is problematic as the prospect of an anal investigation might simultaneously make a person embarrassed, fearful, and disgusted; given that the emotions reliably co-vary, measuring only one emotion may obscure the "active" emotional ingredient(s). Thus, the primary aim of this study was to investigate which of these three emotions-all of which evolved to promote avoidance-predicted CRC screening behaviours and decisions and whether one emotion might be a more salient predictor in this context.

A secondary objective of this work was to examine whether these three emotions arise with respect to specific types of CRC stimuli or tests. All emotions arise in response to specific stimuli $[15,18]$, with screening unlikely to be an exception. Colorectal cancer investigations typically involve differential exposure to the known elicitors of fear (e.g., of a possible cancer diagnosis), embarrassment (e.g., bodily exposure) and disgust (e.g., insertions, exposure to contaminants), suggesting different emotions may be relevant to different aspects of screening. Identifying specific avoidance-promoting emotions in colorectal cancer screening contexts may thus help identify the specific elements of the various screens that people are actually avoiding.

The avoidance-promoting emotions of fear, embarrassment, and disgust have intuitive links to CRC screening. However, disgust remains understudied and these three emotions have typically been examined in isolation from one another. The current report assessed the extent to which fear, embarrassment, and disgust predicted avoidance, over and above known confounds, in contexts related to CRC screening.

\section{Methods}

People aged 45+ years and fluent in English were invited to take part in a study on "Emotions and Human Behaviour". Convenience sampling was used to recruit participants using a combination of flyers posted on university and hospital notice boards, workplace emails, a letterbox drop, and an advertisement in a community newspaper. Participants were offered a $\$ 10$ petrol voucher as remuneration. People who were non-English speaking and aged less than 45 years were excluded from the study.

\section{Measures \\ Demographic and medical factors}

Demographic data together with information regarding whether participants had a regular doctor, and whether a doctor had ever discussed their risk or family history of bowel cancer were gathered.

\section{CRC screening knowledge}

A measure developed to assess knowledge about the United Kingdom CRC screening programme [19] was adapted for local relevance. Participants rate 12 statements related to bowel symptoms and screening as true or false indicators. Correct answers are scored as 1 and items summed to give a total.

\section{Perceptions of CRC risk}

Participants were asked whether they believed their risk of bowel cancer was 'lower', 'about the same', or 'higher' than other men/women their own age as originally used by Weinstein [20]. For the purposes of multivariate analyses, dummy codes were created for lower than average risk (yes $=1$, no $=0$ ) and higher than average risk (yes $=1$, no $=0$ ). 


\section{Disgust propensity and sensitivity-revised scale [DPSS-R;}

[21]]

The DPSS- $\mathrm{R}$ is a 12-item scale measuring propensity (how easily one is disgusted) and sensitivity (how unpleasant someone finds the disgust experience). Previous work has shown the DPSS-R to be valid and reliable and a predictor of health-related avoidance [21, 22]. Internal reliabilities in this sample were good (sensitivity $\alpha=.78$; propensity $\alpha=.80$ ).

\section{Disgust sensitivity-revised scale [DS-R; [23]]}

Whereas the DPSS-R assesses propensity and sensitivity of disgust, the DS-R discriminates between different types of disgust elicitors - namely animal-reminder, contamination, and core disgust. The 27-item measure asks participants to rate from 0 to 4 how disgusting they find a variety of experiences and calculates mean scores for three subscales (animal-reminder, contamination, and core); higher scores indicate greater disgust sensitivity for each of these sources. The DS-R has good internal consistency and validity [24-26], and predicts disgust-generated avoidance in experimental work investigating avoidance in colorectal cancer contexts $[25,27,28]$. Internal consistency was adequate in the current study; core $\alpha$ $=.79$, animal-reminder $\alpha=.73$, contamination $\alpha=.66$.

\section{Differential emotions scale [DES; [29]]}

The DES is a 30-item scale containing three items for each of 10 trait emotions. Using a 1 to 5 scale, participants rate the frequency with which they experience each emotion in their daily life. Mean scores for each subscale provide a score for individual emotions, with higher scores indicating more frequent experiences of that emotion. The disgust, fear, and shame subscales of the DES have been associated with CRC embarrassment [15]. Internal reliability for these subscales were adequate (shame $\alpha=.76$, fear $\alpha=.88$, disgust $\alpha=.70$ ).

\section{Emotional barriers to bowel screening (EBBS)}

Given the absence of a measure to specifically assess multiple emotional barriers to CRC screening, a scale was developed for the study. Development of the EBBS was based on theory suggesting that emotions of fear, embarrassment, and disgust were of greatest relevance $[15,30]$. Twenty items, each assessing one specific emotional barrier to CRC screening were developed by an experienced team of clinicians, psychologists, and researchers. Participants rate between 1 and 5 the extent to which they experience each emotion: 'faecal' disgust (generated by faecal exposure); insertion disgust (elicited by insertion of objects into the anus); embarrassment (related to the social context of screening); and fear of a negative outcome (worries about the potential for a cancer diagnosis). Earlier presentation of preliminary findings using the EBBS led to it being used in another study which suggested the EBBS may be unidimensional [31]. However, confirmatory factor analysis in the current sample using Maximum Likelihood extraction and Direct Oblimin rotation revealed four components with eigenvalues over .70. These components were retained as recommended by Jolliffe [32]. Five items were culled because they co-loaded on to more than one factor and/or had loadings which were less than 0.5 . The 15 remaining items all loaded in a coherent way on to their respective factors (see Table 1) and multicollinearity was within acceptable levels. The overall model fit was significant $\chi^{2}(20)=$ 399.48, $p=.000$. Mean scores were calculated for each subscale. Scales had good reliability; faecal disgust $(\alpha=.90)$, insertion disgust $(\alpha=.94)$, fear of outcome $(\alpha=.84)$, and embarrassment $(\alpha=.89)$.

\section{Hypothetical medical help seeking}

To investigate the possible role of discrete emotional barriers to bowel screening, participants were asked to imagine a scenario where they had been feeling unwell with symptoms for 5 days, with diarrhoea and a dull stomach pain and possibly blood in their stool. The scenario required a decision on making an appointment, knowing that collection of a faecal sample (a disgust elicitor) would be required prior to attendance. Participants were given the option to 'call and make an appointment today' (coded 0) or 'wait another few days' (coded 1).

\section{Bowel screening history}

Participants indicated whether they had ever provided a faecal sample for testing. They also indicated whether they had an invasive bowel screening investigation (i.e., colonoscopy, sigmoidoscopy or CT colonography) in the past 5 years. All responses were coded as no $=0$ and yes $=1$. The sum of the number of reported invasive bowel screening tests was used to create a composite score. As might be expected, data were skewed, hence participants were categorised as having had an invasive bowel screening test or not in the past 5 years.

\section{Analyses}

Statistical analyses began by assessing the concurrent and discriminant validity of the EBBS subscales. Next, relationships among the measures of emotion using Pearson's correlations were assessed using Bonferroni adjusted alpha levels of .001 per test (.05/38). Relationships between emotion measures and screening outcomes were conducted using Spearman's rho (outcome variables were all non-normally distributed). Next, to investigate whether fear of outcome, embarrassment, or disgust predicted screening, a series of step-wise logistic 
Table 1 Factor loadings based on maximum likelihood extraction with direct oblimin rotation for the EBBS

\begin{tabular}{|c|c|c|c|c|c|}
\hline & & $\begin{array}{l}\text { Fear of } \\
\text { outcome }\end{array}$ & Embarrassment & $\begin{array}{l}\text { Insertion } \\
\text { disgust }\end{array}$ & $\begin{array}{l}\text { Faecal } \\
\text { disgust }\end{array}$ \\
\hline 1 & Collecting a sample of my own faeces/poo on a swab stick is really nasty & & & & .658 \\
\hline 2 & The idea of posting a sample of my faeces to my doctor or a laboratory is embarrassing & & & & \\
\hline 3 & The idea of putting anything, even diagnostic equipment into my anus is disgusting & & & -.630 & \\
\hline 4 & I am afraid that giving a stool sample might lead to discovering I have cancer & .831 & & & \\
\hline 5 & I would be so concerned about being diagnosed with bowel cancer that I would avoid testing & 641 & & & \\
\hline 6 & The idea of having to gather a sample of my own faeces makes me feel sick & & & & .835 \\
\hline 7 & Having anything guided up my bottom and into my bowel is disgusting & & & -.886 & \\
\hline 8 & Holding a container of my own faeces (poo) is disgusting & & & & .578 \\
\hline 9 & I would worry that stool testing would find something wrong with me & .948 & & & \\
\hline 10 & Giving a stool/faecal sample for testing is really embarrassing & & .507 & & \\
\hline 11 & The idea of having a short, lighted tube inserted into my anus is gross & & & -.960 & \\
\hline 12 & Imagining that other people know I am collecting stool samples for testing would be embarrassing & & .780 & & \\
\hline 13 & Collecting my own faeces/poo is so disgusting I think I would gag & & & & .582 \\
\hline 14 & I feel uncomfortable when a doctor or nurse describes bowel screening & & & & \\
\hline 15 & I feel anxious when I think about conducting a stool test & & & & \\
\hline 16 & Imagining the feeling of having a screening instrument inserted into my rectum makes me feel ill & & & -.822 & \\
\hline 17 & I would feel humiliated if someone found a faecal collection kit I had been given & & .715 & & \\
\hline 18 & The possibility that collecting faeces for a bowel test might be a bit messy is revolting & & & & \\
\hline 19 & I am afraid that I might hurt myself somehow during stool collection & & & & \\
\hline 20 & Having to insert preparatory medications into my bottom before a bowel cancer test is disgusting & & & -.566 & \\
\hline
\end{tabular}

Note. Loadings of less than .5 are suppressed

regression models were run assessing whether participants a) chose to delay or not in the medical helpseeking scenario, b) had ever provided a faecal sample, and c) had an invasive bowel screening test in the past 5 years. Given the importance of age to the frequency of medical investigation and the known gender differences in bowel screening uptake [15], age and sex were entered as potential confounds at Step 1, as were other variables previously shown to predict screening including subjective risk and whether participants had discussed bowel cancer risk with a doctor [33]. At Step 2, the four EBBS subscales were entered.

\section{Results}

The questionnaire was completed by 306 people (Table 2) with the majority of data $(84 \% ; n=257)$ collected over twelve months (Nov 2011 to Nov 2012). A further 48 participants completed their questionnaires sixteen months later over 2 days in March 2014 following a newspaper interview with one of the study researchers.

Participants were offered the opportunity to complete the questionnaire either online or in written form; the majority chose the online format $(88.2 \%, n=269)$ which was accessed through either an electronic link (i.e., emails, online newspaper article) or the URL specified in print format (i.e., flyers, newspaper advertisement). Of the 298 people who commenced the online survey, 90 . $3 \%(n=269)$ completed the questionnaire. One person was excluded from analyses because of a prior diagnosis of CRC. Ages ranged between 45 and 88 years (median = 55 years) with the majority being female (77\%).

As is common, measures of emotion were correlated (Table 3). However, greater discrimination was revealed when we examined associations between emotions and the CRC screening variables. Consistent with theory suggesting that emotions related to specific screening elicitors would be better predictors than general dispositions $[15,18]$, EBBS subscales were more consistently and more strongly associated with self-reported bowel health outcomes than the more general measures of emotion (i.e., the DS-R, DPSS-R, and the DES subscales; see Table 4). Given the relative strength of these links, multivariate analyses proceeded with the EBBS subscales alone.

In the first model, the predictors of medical helpseeking in the hypothetical presence of bowel symptoms were assessed. Whilst the model was not significant at Step $1, \chi^{2}(2, N=303)=10.71, p=.098$, it was significant with the addition of the EBBS subscales at Step 2, $x^{2}=$ $57.88, p=.000$ (Table 5) and explained $24.3 \%$ of the 
Table 2 Study measures

\begin{tabular}{ll}
\hline Measure & \\
\hline Age: Mean (SD) & \\
Gender: & \\
Male & $72(23.6 \%)$ \\
Female & $233(76.40)$ \\
Marital status: & \\
Single & $35(11.5 \%)$ \\
Married/cohabiting & $201(65.9 \%)$ \\
Separated/divorced & $52(17.0 \%)$ \\
Widowed & $16(5.2 \%)$ \\
Ethnicity: & \\
NZ European & $244(80.0 \%)$ \\
NZ Maori & $15(4.9 \%)$ \\
Pacific & $10(3.3 \%)$ \\
Asian & $12(3.9 \%)$ \\
Other & $24(7.9 \%)$ \\
Completed an invasive bowel screening test in last five years: \\
Colonoscopy & $28(9.2 \%)$ \\
Sigmoidoscopy & $67(22.0 \%)$ \\
CT colonography & $24(7.9 \%)$ \\
Ever provided a faecal sample for testing & $130(42.6 \%)$ \\
\hline
\end{tabular}

variance in delays to help seeking (Nagelkerke $R^{2}$ ). Having ever had a discussion with a doctor about colorectal cancer risk predicted lower odds of delaying medical help-seeking (Wald $=4.45, p=.035$ ), whereas greater CRC screening knowledge predicted a greater likelihood of deciding to 'wait another few days' before making an appointment (Wald $=3.98$, $p=.046)$. Greater fear of a negative outcome predicted greater likelihood of delay (Wald $=6.29, p=.012$ ), and screening embarrassment showed a trend in the same direction (Wald $=3.28, p=.070$ ).

Next, the predictors of reporting having previously provided a faecal sample were assessed. This model was significant at Step $1 X^{2}(6, N=304)=34.35, p=.000$ and explained $14.3 \%$ (Nagelkerke $R^{2}$ ) of the variance in having ever provided a faecal sample; older age (Wald $=12.01$, $p=.001$ ) and physician discussion (Wald $=8.08, p=.004$ ) predicted a greater likelihood of having given a sample whereas, perceptions of low colorectal cancer risk were associated with a lower likelihood (Wald $=4.44, p=.035$ ). The model was strengthened at Step 2 with the entry of the EBBS subscales, $X^{2}=44.97, p=.000$ and explained 18 . $5 \%$ of the variance (Nagelkerke $R^{2}$ ). Having discussed risk with a doctor (Wald $=6.85, p=.009$ ), older age (Wald $=9$. $35, p=.002$ ), and greater embarrassment (Wald $=0.49$, $p=.017)$ predicted a greater likelihood of having provided a sample, whereas perceptions of lower risk (Wald $=4.29$, $p=.038$ ) predicted, and greater insertion disgust (Wald = $3.28, p=.070$ ) marginally predicted, a lower likelihood.

Finally, the predictors of reporting having had an invasive bowel investigation in the past 5 years were

Table 3 Pearson correlations, means and standard deviations of emotion measures

\begin{tabular}{|c|c|c|c|c|c|c|}
\hline Measure & Mean & SD & Faecal disgust & Insertion disgust & Fear of outcome & Embarrassment \\
\hline \multicolumn{7}{|l|}{ EBBS subscales: } \\
\hline Faecal disgust & 1.98 & 0.98 & & & & \\
\hline Insertion disgust & 2.09 & 1.05 & $0.80^{*}$ & & & \\
\hline Fear of outcome & 1.80 & 0.94 & $0.51^{*}$ & $0.51^{*}$ & & \\
\hline Embarrassment & 1.95 & 1.02 & $0.78^{*}$ & $0.74^{*}$ & $0.51^{*}$ & \\
\hline \multicolumn{7}{|l|}{ DS-R subscales: } \\
\hline Core & 2.05 & 0.67 & $0.44^{*}$ & $0.40^{*}$ & $0.23^{*}$ & $0.42^{*}$ \\
\hline Animal-reminder & 1.62 & 0.78 & $0.43^{*}$ & $0.38^{*}$ & $0.29^{*}$ & $0.36^{*}$ \\
\hline Contamination & 1.40 & 0.80 & $0.39^{*}$ & $0.37^{*}$ & $0.27^{*}$ & $0.33^{*}$ \\
\hline \multicolumn{7}{|l|}{ DPSS-R subscales: } \\
\hline Propensity & 2.58 & 0.52 & $0.46^{*}$ & $0.42^{*}$ & $0.32^{*}$ & $0.39^{*}$ \\
\hline Sensitivity & 1.97 & 0.62 & $0.39^{*}$ & $0.38^{*}$ & $0.32^{*}$ & $0.40^{*}$ \\
\hline \multicolumn{7}{|l|}{ DES subscales: } \\
\hline Fear & 5.87 & 2.38 & $0.24^{*}$ & $0.26^{*}$ & $0.21^{*}$ & $0.29^{*}$ \\
\hline Disgust & 5.56 & 1.93 & $0.36^{*}$ & $0.42^{*}$ & $0.34^{*}$ & $0.32^{*}$ \\
\hline Shame & 6.11 & 2.18 & $0.31^{*}$ & $0.31^{*}$ & $0.29^{*}$ & $0.29^{*}$ \\
\hline
\end{tabular}


Table 4 Spearman's rho correlations between emotion measures and bowel screening behaviours

\begin{tabular}{|c|c|c|c|}
\hline Measure & Decision to delay seeking medical help & Ever provided a faecal sample & Invasive bowel screening test in last 5 years \\
\hline \multicolumn{4}{|l|}{ EBBS subscales: } \\
\hline Faecal disgust & $0.31^{* *}$ & $-0.13^{*}$ & $-0.12^{*}$ \\
\hline Insertion disgust & $0.28^{* *}$ & $-0.18^{* *}$ & $-0.24^{* *}$ \\
\hline Fear of outcome & $0.31^{* *}$ & -0.09 & $-0.13^{*}$ \\
\hline Embarrassment & $0.32^{* *}$ & -0.04 & $-0.16^{* *}$ \\
\hline \multicolumn{4}{|l|}{ DS-R subscales: } \\
\hline Core & 0.07 & -0.02 & -0.05 \\
\hline Animal-reminder & 0.08 & $-0.11^{+}$ & -0.07 \\
\hline Contamination & 0.09 & -0.03 & 0.02 \\
\hline \multicolumn{4}{|l|}{ DPSS-R subscales: } \\
\hline Propensity & $0.10^{+}$ & 0.06 & -0.07 \\
\hline Sensitivity & $0.14^{*}$ & -0.02 & -0.07 \\
\hline \multicolumn{4}{|l|}{ DES subscales: } \\
\hline Fear & $0.15^{*}$ & 0.00 & 0.04 \\
\hline Disgust & $0.14^{*}$ & $-0.16^{*}$ & -0.04 \\
\hline Shame & $0.19^{* *}$ & -0.05 & -0.04 \\
\hline
\end{tabular}

${ }^{* *} p<.01,{ }^{*} p<.05,{ }^{+} p<.10$

assessed. This model was significant at Step $1, \mathrm{X}^{2}(6, N=$ $304)=95.32, p=.000$ and explained $38.2 \%$ (Nagelkerke $R^{2}$ ) of the variance; older age (Wald $=13.66, \mathrm{p}=.000$ ) , having discussed screening with a doctor (Wald $=38$. 27, $p=.000$ ), and greater CRC knowledge (Wald $=4.15$, $p=.042$ ), predicted a greater likelihood of reporting a prior investigation. The model was strengthened at Step 2, with the EBBS subscales $x^{2}=107.22, p=.000$ and explained $42.2 \%$ of the variance. Greater insertion disgust predicted a lower likelihood of reporting an invasive bowel screening test in the past 5 years $($ Wald $=8.09, p=.004)$. Older age (Wald $=9.90, p=.002)$ and having discussed risk with a doctor continued to predict greater likelihood (Wald $=33.96, \quad p=.000$ ), while CRC knowledge was no longer significant at this second step.

\section{Discussion}

Participation rates of CRC screening programmes fall consistently below recommended levels and people delay presenting to medical care with bowel symptoms [34]; results of this research suggest that alongside demographic and medical variables, emotions may also be a factor. Unsurprisingly, age, discussions with a doctor,

Table 5 Step-wise logistic regression: Final (Step 2) models showing the multivariate predictors of bowel screening behaviours

\begin{tabular}{|c|c|c|c|c|c|c|}
\hline \multirow[b]{2}{*}{ Variable } & \multicolumn{2}{|c|}{ Decision to delay seeking medical help } & \multicolumn{2}{|l|}{$\begin{array}{l}\text { Ever provided } \\
\text { a faecal sample }\end{array}$} & \multicolumn{2}{|c|}{$\begin{array}{l}\text { Invasive bowel screening } \\
\text { test in past } 5 \text { years }\end{array}$} \\
\hline & Odds Ratio (95\% Cl) & $p$ value & Odds Ratio (95\% Cl) & $p$ value & Odds Ratio (95\% Cl) & $p$ value \\
\hline$\overline{S e x}$ & $1.22(0.62-2.39)$ & .560 & $1.80(0.98-3.31)$ & .059 & $1.84(0.85-3.97)$ & .123 \\
\hline Age & $1.00(0.97-1.04)$ & .843 & $1.05(1.02-1.08)$ & .002 & $1.06(1.02-1.10)$ & .002 \\
\hline Perceived low colorectal cancer risk ${ }^{2}$ & $1.31(0.68-2.54)$ & .418 & $0.51(0.27-0.96)$ & .038 & $0.52(0.22-1.22)$ & .133 \\
\hline Perceived high colorectal cancer risk ${ }^{3}$ & $1.06(0.43-2.62)$ & .906 & $0.51(0.23-1.16)$ & .107 & $1.76(0.71-4.36)$ & .225 \\
\hline Discussed with doctor ${ }^{4}$ & $0.47(0.24-0.95)$ & .035 & $2.16(1.21-3.85)$ & .009 & $6.79(3.57-12.94)$ & .000 \\
\hline Colorectal cancer screening knowledge & $1.19(1.00-1.42)$ & .046 & $0.99(0.85-1.15)$ & .868 & $1.14(0.93-1.38)$ & .206 \\
\hline EBBS fear of outcome & $1.53(1.10-2.13)$ & .012 & $0.89(0.64-1.24)$ & .484 & $0.92(0.60-1.42)$ & .718 \\
\hline EBBS embarrassment & $1.49(0.97-2.29)$ & .070 & $1.73(1.10-2.70)$ & .017 & $1.60(0.92-2.77)$ & .097 \\
\hline EBBS insertion disgust & $0.91(0.57-1.46)$ & 698 & $0.66(0.42-1.04)$ & .070 & $0.41(0.22-0.76)$ & .004 \\
\hline EBBS faecal disgust & $1.47(0.88-2.45)$ & .142 & $0.75(0.46-1.24)$ & .265 & $1.12(0.58-2.17)$ & .734 \\
\hline
\end{tabular}

${ }_{1}^{1} 0=$ female $(n=233), 1=$ male $(n=72) ;{ }^{2} 0=$ not perceived low CRC risk $(n=236), 1=$ perceived low CRC risk low risk $(n=69) ;{ }^{3} 0=$ not perceived high CRC risk $(n=266), 1=$ perceived high CRC risk $(n=39) ;{ }^{4} 0=$ never discussed CRC risk with doctor $(n=207), 1=$ had discussed CRC risk with doctor $(n=98)$ 
and perceptions of bowel cancer risk predicted reports of prior screening and decisions about help-seeking in a hypothetical scenario. More to the point, the addition of emotions consistently increased the models' ability to predict delay or bowel screening avoidance. Greater fear of a detection of cancer predicted the decision to delay attending a doctor's clinic when confronted with suspicious bowel symptoms and greater insertion disgust predicted a lower likelihood of having had a prior bowel screening investigation. Interestingly, greater embarrassment was associated with a greater likelihood of reporting having provided a faecal sample in the past. Below, these findings are linked to prior work and discussed more fully, before the implications of these results for CRC screening programmes are considered.

Our findings extend previous work that identified the role of faecal disgust as a barrier to bowel screening [31] by introducing the possibility that specific emotional responses might impact screening behaviours in different ways, and that the source of emotion is important. Our data imply that fear, embarrassment, and disgust all have a role to play in our understanding of CRC screening avoidance. In each analysis, emotional barriers regarding testing or screening predicted screening over and above medical and demographic factors. For example, fear of a negative outcome was associated with greater avoidance where people imagined taking a container of faeces to a doctor's clinic. Why it was this emotion rather than disgust in this scenario is unclear. Arguably, it might have been that the fear of a cancer diagnosis outweighed the potential disgust related to the collection of the faeces itself.

In contrast, when predicting prior CRC investigations, it was disgust related to anal insertions rather than to faecal exposure that best predicted avoidance. In some ways this finding is inconsistent with suggestions that faecal exposure is the central emotional impediment to bowel screening $[35,36]$, although prior studies have not separated these two sources of disgust response. Hence, whilst we do not discount the relevance of faecal aversion (particularly to some forms of testing), it might be that measures of faecal aversion co-vary with insertion concerns, or that for some tests concerns about faeces "pale in comparison" to feelings regarding inserting medical apparatus into the anus. Depending on the particular CRC screen that is being targeted, campaigns that seek to normalise exposure to faeces might be boosted with messages aimed at minimising concerns about anal insertions.

Interestingly, the direction of relationships differed across emotions and variables. As noted above, insertion disgust predicted a lower likelihood of having provided a faecal sample (i.e., greater avoidance), whereas embarrassment predicted a greater likelihood of having provided a sample (presumably, less avoidance). Whilst the latter finding seems initially counterintuitive, this result is not without precedent. In one study, while faecal/ rectal embarrassment predicted a lower odds of a CRC screen, a more general embarrassment regarding examination intimacy predicted (albeit marginally) greater odds of a previous screen [15]. It might be that some forms of embarrassment are associated with greater negative affect or health anxiety, and it is this cluster of characteristics that makes a person more likely to screen (i.e., screening provides reassurance to those that worry). A further possibility is that the direction of the relationship between embarrassment and screening is the other way around-it is not that embarrassment predicts screening so much as previous exposure to faecal collection leads to a greater recognition of the embarrassment involved. Whilst evaluating these possibilities is beyond the scope of this work, our findings clearly reinforce the need to differentiate fear, disgust, and embarrassment in both measurement as well as their impact on cancer screening behaviours.

On the surface, identifying the 'practical' reasons for CRC screening non-attendance (access, transport etc.) should address impediments to screening. However, screening programmes have consistently struggled to recruit despite efforts to address these problems [7]. Data from this report suggest that emotions matter in CRC screening contexts. By understanding the specific emotions at play, messages and interventions can be tailored to address the most potent deterrents to screening behaviour. As noted, non-attendance due to fear of a diagnosis will require a different message than an intervention aimed at reducing avoidance due to disgust regarding the procedure itself [18]. Thus, interventions such as media campaigns, invitation letters, and communications from the staff who greet patients and carry out procedures could be tailored to address the particular emotional deterrents of fear, embarrassment, and disgust. Whilst, interventions that utilise such emotions have not been previously studied, recent research indicates that exposure to other emotions (i.e., anticipated regret) can increase CRC screening rates in people with low intentions to screen [17].

Although this study makes a useful contribution to the literature by demonstrating the role of fear, embarrassment and disgust in CRC investigations, it is not without its limitations. First, the timeline of data collection creates the possibility of historical confounds influencing responses. To check for this, we ran alternative analyses excluding the 48 participants gathered in 2014, and results remained the same apart from the expected marginalisation due to loss of power on two of the measures. Over the research time period no bowel screening programmes were being offered (aside from a single pilot 
programme in one of the local health boards), and so, would have been relatively unknown at the time. We therefore did not ask about intentions to screen, however, future research would ideally include an intentionto-screen question. Due to the way participants were recruited we were unable to estimate a response rate which limits our ability to know the extent to which our results might be biased. We also did not collect data about education level and so have no way of knowing whether the sample represents the CRC screening population. What we do know is that our gender split (76\% female / $24 \%$ male) is not representative and, given the differences between men and women in response to cancer screening [37], this is a limitation of the work. The majority of our sample chose to complete the questionnaire online meaning we may have differentially accessed a more electronically-minded sample that does not necessarily reflect the population of people aged $45+$. The study also employed a cross-sectional, retrospective design, and whilst emotions in this study predicted previous screening behaviours and responses to a hypothetical scenario, we cannot be sure whether precisely the same pattern would be found for future screens; there is certainly evidence for the inaccuracies in people's reporting of their past screening uptake [38]. Future research would benefit by prospectively evaluating dispositional and attitudinal factors prior to patients being offered CRC screening and might also more systematically consider the difference between anticipated versus actual emotion. Bowel screening procedures can be anticipated to be much worse than the actual experience [39], and enquiry into the extent that such over-estimations in anticipated emotion influence future behaviours may be important.

Future research might also investigate the importance of ethnicity or race in analyses. Disparities in screening are well known $[37,40]$ and the populations with the poorest survival statistics typically have lower screening rates. The extent to which avoidance-promoting emotions play a greater or lesser role in these populations is an important question for future studies. It might also be that the language to describe these emotions might vary across populations. For instance, words like 'nasty' and 'gross' may not be the language of disgust across all groups. Research that identifies how communications and screening messages might be targeted to address emotional sensitivities has potential to increase screening among these at-risk groups.

\section{Conclusions}

This report suggests that continuing to base CRC screening communications on the assumption that people behave rationally risks ignoring the elephant in the room-people get frightened, embarrassed, and disgusted by screenings and cancer. By understanding the emotional substrates for avoidance behaviours in CRC screening, we can tap into another layer of motivation to inform screening development, communication, and outreach. Importantly, however, it is not simply that emotions per se matter but, rather, that particular emotions matter-namely fear, embarrassment, and disgust. Understanding how specific emotions may impact screening decisions and behaviour is an important direction for future work.

\section{Abbreviations \\ CRC: Colorectal cancer; CT: Computed tomography; DES: Differential emotions scale; DPSS: Disgust propensity and sensitivity scale - revised; DS- R: Disgust sensitivity - revised scale; EBBS: Emotional barriers to bowel screening scale; URL: Universal resource locator}

\section{Funding}

LR was funded to conduct this work by a University of Auckland Senior Health Doctoral Scholarship.

\section{Availability of data and materials}

The datasets used and analysed during the current study are available from the corresponding author on reasonable request.

\section{Authors' contributions}

Study conception and design: $L R, I B$ and NC; Acquisition of data: $L R$; Analysis and interpretation of data: $L R, I B$ and NC; Writing manuscript: $L R, I B$, and NC. All authors have read and approved the final manuscript.

\section{Ethics approval and consent to participate}

Ethics approval was obtained from the University of Auckland Human Participants Ethics Committee (reference number 7625). Informed consent was obtained in writing from participants who completed the paper version of the questionnaire or electronically from participants who completed the questionnaire online, and all procedures were in accordance with the ethical standards of the responsible committee on human experimentation (institutional and national) and with the Helsinki Declaration of 1975, as revised in 2000.

\section{Competing interests}

The authors declare that they have no competing interests.

\section{Publisher's Note}

Springer Nature remains neutral with regard to jurisdictional claims in published maps and institutional affiliations.

\section{Author details}

'Department of Psychological Medicine, The University of Auckland, Private bag 92019, Victoria Street West, Auckland 1142, New Zealand. ${ }^{2}$ Department of Surgery, The University of Auckland, Private Bag 92019, Victoria Street West, Auckland 1142, New Zealand.

Received: 5 October 2017 Accepted: 23 April 2018

Published online: 03 May 2018

\section{References}

1. Arnold M, Sierra MS, Laversanne M, Soerjomataram I, Jemal A, Bray F. Global patterns and trends in colorectal cancer incidence and mortality. Gut. 2017; 66(4):683-91.

2. Whyte S, Chilcott J, Halloran S. Reappraisal of the options for colorectal cancer screening in England. Color Dis. 2012;14(9):e547-61.

3. Schreuders EH, Ruco A, Rabeneck L, Schoen RE, Sung JJY, Young GP, Kuipers EJ. Colorectal cancer screening: a global overview of existing programmes. Gut. 2015;64(10):1637.

4. Lew J-B, St John DJB, Xu X-M, Greuter MJE, Caruana M, Cenin DR, He E, Saville M, Grogan P, Coupé VMH, et al. Long-term evaluation of benefits, harms, and cost-effectiveness of the National Bowel Cancer Screening 
Program in Australia: a modelling study. Lancet Public Health. 2017;2(7): e331-40.

5. Rex DK, Boland CR, Dominitz JA, Giardiello FM, Johnson DA, Kaltenbach T, Levin TR, Lieberman D, Robertson DJ. Colorectal cancer screening: recommendations for physicians and patients from the U.S. multi-society task force on colorectal Cancer. Am J Gastroenterol. 2017:112:1016.

6. Baron RC, Rimer BK, Coates RJ, Kerner J, Kalra GP, Melillo S, Habarta N, Wilson KM, Chattopadhyay S, Leeks K: Client-directed interventions to increase community access to breast, cervical, and colorectal cancer screening: a systematic review. Am J Prev Med 2008, 35(1, Supplement):S56-S66.

7. Von Wagner C, Good A, Whitaker KL, Wardle J. Psychosocial determinants of socioeconomic inequalities in cancer screening participation: a conceptual framework. Epidemiol Rev. 2013;33(1):135-47.

8. Klabunde C, Blom J, Bulliard J-L, Garcia M, Hagoel L, Mai V, Patnick J, Rozjabek H, Senore C, Törnberg S. Participation rates for organized colorectal cancer screening programmes: an international comparison. J Med Screening. 2015;22(3):119-26.

9. Consedine NS, Magai C, Neugut Al. The contribution of emotional characteristics to breast cancer screening among women from six ethnic groups. Prev Med. 2004;38(1):64-77.

10. Levin B, Lieberman DA, McFarland B, Smith RA, Brooks D, Andrews KS, Dash C, Giardiello FM, Glick S, Levin TR. Screening and surveillance for the early detection of colorectal cancer and adenomatous polyps, 2008: a joint guideline from the American Cancer Society, the US multi-society task force on colorectal Cancer, and the American College of Radiology. CA Cancer J Clin. 2008:58(3):130-60

11. Consedine NS, Krivoshekova YS, Harris CR. Bodily embarrassment and judgment concern as separable factors in the measurement of medical embarrassment: psychometric development and links to treatment-seeking outcomes. Brit J Health Psychol. 2007;12:439-62.

12. Reynolds LM, Consedine NS, Pizarro DA, Bissett IP. Disgust and behavioral avoidance in colorectal cancer screening and treatment: a systematic review and research agenda. Cancer Nurs. 2013;36(2):122-30.

13. Klabunde CN, Vernon SW, Nadel MR, Breen N, Seeff LC, Brown ML. Barriers to colorectal cancer screening: a comparison of reports from primary care physicians and average-risk adults. Med Care. 2005;43(9):939-44.

14. Walsh JME, Kaplan CP, Nguyen B, Gildengorin G, McPhee SJ, Pérez-Stable EJ. Barriers to colorectal Cancer screening in Latino and Vietnamese Americans. J Gen Int Med. 2004;19(2):156-66.

15. Consedine NS, Ladwig I, Reddig MK, Broadbent EA. The many faeces of colorectal cancer screening embarrassment: preliminary psychometric development and links to screening outcome. Brit J Health Psychol. 2011;

16. Chambers JA, Callander AS, Grangeret R, O'Carroll RE. Attitudes towards the Faecal occult blood test (FOBT) versus the Faecal immunochemical test (FIT) for colorectal cancer screening: perceived ease of completion and disgust. BMJ Cancer. 2016;16:1.

17. O'Carroll RE, Chambers J, Brownlee L, Libby G, Steele R. Anticipated regret to increase uptake of colorectal cancer screening (ARTICS): a randomised controlled trial. Soc Sci Med. 2015;142:118-27.

18. Consedine NS, Adjei BA, Ramirez PM, McKiernan J. An object lesson: differences in source determine the relations that trait anxiety, prostate cancer worry, and fear of screening hold with prostate screening frequency. Cancer Epidemiol Biomark Prev. 2008:17(7):1631-9.

19. von Wagner C, Semmler C, Good A, Wardle J. Health literacy and selfefficacy for participating in colorectal cancer screening: the role of information processing. Patient Educ Counsel. 2009;75(3):352-7.

20. Weinstein ND. Unrealistic optimism about susceptibility to health problems: conclusions from a community-wide sample. J Behav Med. 1987;10(5):481-500.

21. van Overveld M, de Jong PJ, Peters ML. The disgust propensity and sensitivity scale - revised: its predictive value for avoidance behavior. Personal Individual Diff. 2010;49(7):706-11

22. Brady RE, Cisler JM, Lohr JM. Specific and differential prediction of health anxiety by disgust sensitivity and propensity. Anxiety, Stress Coping. 2014; 27(1):90-9.

23. van Overveld $M$, de Jong $P$, Peters $M L$, Schouten $E$. The disgust scale-R: a valid and reliable index to investigate separate disgust domains? Personal Individ Differ. 2011;51(3):325-30.

24. Fan Q, Olatunji BO. Individual differences in disgust sensitivity and healthrelated avoidance: examination of specific associations. Personal Individ Differ. 2013;55(5):454-8.
25. Olatunji BO, Moretz MW, McKay D, Bjorklund F, de Jong PJ, Haidt J, Hursti TJ, Imada S, Koller S, Mancini F, et al. Confirming the three-factor structure of the disgust-scale - revised in eight countries. J Cross-Cultural Psychol. 2009:40:234-54.

26. Reynolds LM, McCambridge SA, Bissett IP, Consedine NS. Trait and state disgust: an experimental investigation of disgust and avoidance in colorectal cancer decision scenarios. Health Psychol. 2014;33(12):1495-506.

27. Reynolds LM, Bissett IP, Consedine NS. Predicting the patients that will struggle with anal incontinence: sensitivity to disgust matters. Color Dis. 2015;17:73-80.

28. Reynolds LM, Bissett IP, Porter D, Consedine NS. The 'ick' factor matters: disgust prospectively predicts avoidance in chemotherapy patients. Annals of Behavioral Med. 2016;50(6)935-945.

29. Izard CE, Libero DZ, Putnam P, Haynes OM. Stability of emotion experiences and their relations to traits of personality. J Personality Soc Psychol May. 1993;64(5):847-60

30. Consedine NS, Moskowitz JT. The role of discrete emotions in health outcomes: a critical review. Applied and Prev Psychol. 2007;12(2):59-75.

31. Davis M, Oaten M, Occhipinti S, Chambers SK, Stevenson RJ. An investigation of the emotion of disgust as an affective barrier to intention to screen for colorectal cancer. European J Cancer Care. 2017;26(4)e12582.

32. Jolliffe IT. Discarding variables in a principal component analysis, I: Artifical data. Applied Stat. 1972;21 (2):160-73.

33. Meissner HI, Breen N, Klabunde CN, Vernon SW. Patterns of colorectal cancer screening uptake among men and women in the United States. Cancer Epidemiol Biomarkers Prev. 2006;15(2):389-94.

34. Hamilton W, Sharp D. Diagnosis of colorectal cancer in primary care: the evidence base for quidelines. Fam Pract. 2004;21 (1):99-106.

35. Chapple A, Ziebland S, Hewitson P, McPherson A. What affects the uptake of screening for bowel cancer using a faecal occult blood test (FOBt): a qualitative study. Soc Sci Med. 2008;66(12):2425-35.

36. Friedemann-Sanchez G, Griffin JM, Partin MR. Gender differences in colorectal cancer screening barriers and information needs. Health Expect. 2007;10(2):148-60

37. Consedine NS, Reddig MK, Ladwig I, Broadbent EA. Gender and ethnic differences in colorectal cancer screening embarrassment and physician gender preferences. Oncol Nurs Forum. 2011;38(6):E409-17.

38. Rauscher GH, Johnson TP, Cho YI, Walk JA. Accuracy of self-reported cancerscreening histories: a meta-analysis. Cancer Epidemiol Biomarkers Prev. 2008; 17(4):748-57.

39. Von Wagner C, Knight $\mathrm{K}$, Halligan S, Atkin W, Lilford R, Morton D, Wardle J. Patient experiences of colonoscopy, barium enema and CT colonography: a qualitative study. Brit J Radiol. 2009;82(973):13-9.

40. Austin KL, Power E, Solarin I, Atkin WS, Wardle J, Robb KA. Perceived barriers to flexible sigmoidoscopy screening for colorectal cancer among UK ethnic minority groups: a qualitative study. J Med Screen. 2009;16(4):174-9.

Ready to submit your research? Choose BMC and benefit from

- fast, convenient online submission

- thorough peer review by experienced researchers in your field

- rapid publication on acceptance

- support for research data, including large and complex data types

- gold Open Access which fosters wider collaboration and increased citations

- maximum visibility for your research: over $100 \mathrm{M}$ website views per year

At BMC, research is always in progress.

Learn more biomedcentral.com/submissions 